\title{
DNA and Polyphosphate in Directed Proteolysis for DNA Replication Control
}

\author{
Malgorzata Ropelewska, Marta H. Gross ${ }^{\dagger}$ and lgor Konieczny* \\ Laboratory of Molecular Biology, Intercollegiate Faculty of Biotechnology of University of Gdańsk and Medical University \\ of Gdańsk, Gdańsk, Poland
}

OPEN ACCESS

Edited by:

Torsten Waldminghaus, University of Marburg, Germany

Reviewed by:

Dhruba Chattoraj, National Institutes of Health (NIH),

United States

Kristina Jonas,

Stockholm University, Sweden

Ulf Gerth,

University of Greifswald, Germany

*Correspondence: Igor Konieczny

igor.konieczny@ug.edu.pl

tPresent address: Marta H. Gross, Chromosome Replication Laboratory, The Francis Crick Institute, London, United Kingdom

Specialty section:

This article was submitted to Evolutionary and Genomic Microbiology

a section of the journal Frontiers in Microbiology

Received: 21 July 2020 Accepted: 10 September 2020 Published: 02 October 2020

Citation:

Ropelewska M, Gross MH and Konieczny I (2020) DNA and Polyphosphate in Directed Proteolysis for DNA Replication Control. Front. Microbiol. 11:585717. doi: 10.3389/fmicb.2020.585717
The strict control of bacterial cell proliferation by proteolysis is vital to coordinate cell cycle processes and to adapt to environmental changes. ATP-dependent proteases of the AAA + family are molecular machineries that contribute to cellular proteostasis. Their activity is important to control the level of various proteins, including those that are essential for the regulation of DNA replication. Since the process of proteolysis is irreversible, the protease activity must be tightly regulated and directed toward a specific substrate at the exact time and space in a cell. In our mini review, we discuss the impact of phosphate-containing molecules like DNA and inorganic polyphosphate (PolyP), accumulated during stress, on protease activities. We describe how the directed proteolysis of essential replication proteins contributes to the regulation of DNA replication under normal and stress conditions in bacteria.

Keywords: DNA replication, replication initiators, proteolysis, polyphosphate, lon protease

\section{INTRODUCTION}

Several mechanisms responsible for the control of DNA replication in bacteria were described (Zakrzewska-Czerwińska et al., 2007). Most of those mechanisms aim at decreasing the availability of active replication protein, e.g., by regulating the transcription (Gora et al., 2013), spatial sequestration (Iniesta et al., 2006), or protein inactivation (Kurokawa et al., 1999). It was shown that particular bacterial proteases are involved in the proteolysis of replication proteins and proteins associated with the process of DNA replication (Wickner et al., 1994; Pierechod et al., 2009; Kubik et al., 2012; Karlowicz et al., 2017). The major proteases in bacteria belong to the family of ATPases associated with diverse cellular activities (AAA +). In Escherichia coli, there are four cytosolic proteases (i.e., ClpXP, ClpAP, HslUV, and Lon) (Gottesman, 2003). Bacterial AAA + proteases function efficiently under different growth conditions participating in regulation of several cellular processes. For instance, the intracellular levels of the HslUV protease are increased under heatshock conditions when it has the maximum substrate degradation rate (Burton et al., 2005). In addition to HslUV functions under thermal stress, this protease plays an important role in SOS response caused by DNA damage (Khattar, 1997) and in response to acidic stress (Kannan et al., 2008). ClpXP participates in the response to starvation (Schweder et al., 1996), heat shock, and oxidative stress (Frees et al., 2003). Similarly, ClpAP protease is responsible for the control of regulatory pathways in bacteria and response to proteotoxic stress caused by $\mathrm{pH}$ downshift or high temperature (Jenal and Hengge-Aronis, 2003). Lon protease contributes to genome maintenance during stress (e.g., heat shock or nutrient depletion) by regulating DNA replication (Nicoloff et al., 2007; Jonas et al., 2013; Leslie et al., 2015; Gross and Konieczny, 2020). Furthermore, LonA protease is involved in the tolerance of Actinobacillus pleuropneumoniae to osmotic or oxidative stress 
(Xie et al., 2016). Since proteolysis is irreversible, it must be induced at particular conditions and target specific proteins in a tightly controlled manner. Bacterial AAA + proteases are regulated temporally (Goff and Goldberg, 1987; Jonas et al., 2013), spatially (Simmons et al., 2008), and structurally (Jonas et al., 2013) and by interaction with ligand or adaptors (Goldberg et al., 1980; Wah et al., 2002; Martin et al., 2008; Puri, 2016). Proteases interact with various phosphate-containing molecules including membrane components [e.g., lipopolysaccharide (LPS) (Sugiyama et al., 2013) and cardiolipin (CL) (Minami et al., 2011)], stress-induced factors [e.g., guanosine tetraphosphate ((p)ppGpp) (Osbourne et al., 2014) and inorganic polyphosphate (PolyP) (Kuroda, 2006)], ATP (Charette et al., 1981), and ADP (Waxman and Goldberg, 1985) as well as with DNA (Zehnbauer et al., 1981; Zylicz et al., 1998; Kubik et al., 2012). The protease binding to phosphate-containing molecules may change protease localization, ATPase activity, or substrate specificity, thereby modulating its proteolytic activity (Kubik et al., 2012; Karlowicz et al., 2017; Gross and Konieczny, 2020).

\section{THE IMPACT OF DNA BINDING ON PROTEASE ACTIVITY}

In Escherichia coli, only Lon and ClpAP, but not ClpXP or HslUV, interact with DNA (Kubik et al., 2012). Interaction of Lon with nucleic acid is a conserved property among species (Zehnbauer et al., 1981; Fu and Markovitz, 1998; Lee et al., 2004; Lu et al., 2003). It was demonstrated that the $\alpha$ subdomain in the AAA + module of Brevibacillus thermoruber Lon is involved in DNA binding (Lee et al., 2004, 2014; Lin et al., 2009). In various organisms, Lon has different preference for the type of DNA with which it forms a complex. E. coli Lon binds to doublestranded DNA (dsDNA) in a sequence-non-specific manner (Charette et al., 1984; Nomura et al., 2004). On the contrary, eukaryotic proteases bind single-stranded DNA (ssDNA) or RNA (Fu and Markovitz, 1998; Lu et al., 2003; Liu et al., 2004). Bacillus subtilis LonA is present in the nucleoid under normal growth conditions, while ClpXP is present in cytosol (Simmons et al., 2008). During spore development, LonA changes its localization to the forespore (Simmons et al., 2008). Under heat shock, LonA remains bound to the nucleoid (Simmons et al., 2008). Yet in E. coli when temperature is increased, Lon loses its ability to bind DNA in vitro, although ATP-dependent proteolytic activity is retained (Sonezaki et al., 1995). It is proposed that the Lon presence within the nucleoid allows for the degradation of DNAassociated proteins involved in DNA metabolism. The protease dissociation from DNA upon stress-related factors may provide rapid adaptive mechanism to hamper Lon activity toward specific proteins (Sonezaki et al., 1995).

The interaction of DNA with Lon stimulates its ATPase activity (Charette et al., 1984). At the surface of E. coli Lon ATPase domain, there are located positively charged residues, which are responsible for direct interaction with DNA (Karlowicz et al., 2017). The presence of DNA in a reaction mixture containing Lon and substrate protein enhances protease activity to hydrolyze ATP (Karlowicz et al., 2017). The ATPase activity of Lon mutant defective in DNA interaction is not increased in the presence of substrate and DNA. Hence, it is the direct DNA-Lon interaction that stimulates protease ATPase activity (Karlowicz et al., 2017). It was also demonstrated that Lon nucleoprotein complex formation is essential for the proteolysis of DNA-interacting substrates, but not other substrates (Karlowicz et al., 2017).

The ClpAP proteolysis of DNA-binding substrates is also stimulated by DNA. For example, ParD protein, the component of toxin-antitoxin system of RK2 plasmid (Kubik et al., 2012; Dubiel et al., 2018) is degraded by ClpAP in a DNA-dependent manner (Dubiel et al., 2018). In vitro experiments suggest that it is the protease-DNA interaction, but not substrateDNA interaction, that contributes to the enhanced proteolysis. Although E. coli ClpXP and HslUV do not form nucleoprotein complexes, the addition of DNA to the in vitro reaction mixture affects the proteolysis of particular substrates (Kubik et al., 2012). As opposed to Lon and ClpAP, the process of proteolysis is inhibited by DNA. This may be explained by the ability of substrates to interact directly with DNA, thus hampering their proteolysis.

\section{THE IMPACT OF POLYPHOSPHATE BINDING ON PROTEASE ACTIVITY}

When bacteria encounter stress such as amino acid starvation or oxidative stress, they accumulate inorganic PolyP, which forms granular superstructures and contributes to cell survival (Kuroda et al., 2001). The production of PolyP was initially correlated with the synthesis of second messenger stress molecule, (p)ppGpp, which was shown to inhibit the activity of exopolyphosphatase (PPX), thereby enabling uncontrolled production of PolyP by PolyP kinase (PPK) (Kuroda et al., 1997; Magnusson et al., 2005; Traxler et al., 2008; Rao et al., 2009). Ppk mutants fail to survive in stationary phase and are less resistant to heat or oxidants (Crooke et al., 1994; Rao and Kornberg, 1996). Recent data argue that (p)ppGpp is not required for PolyP synthesis and that transcription factor DksA contributes to the control of PolyP level instead (Gray, 2019). In Caulobacter crescentus, PolyP has been shown to be involved in the regulation of DNA replication during carbon starvation (Boutte et al., 2012). During nitrogen starvation in Pseudomonas aeruginosa, PolyP granule biogenesis is temporally and functionally tied to cell cycle exit indicated by the inhibition of reinitiation of DNA replication, completion of open rounds of DNA replication, segregation of daughter chromosomes, and septation (Racki et al., 2017). PolyP interacts with Escherichia coli Lon via ATPase domain (Nomura et al., 2004), as in the case of DNA (Karlowicz et al., 2017), which implies that both phosphate-containing molecules can compete for Lon binding. Indeed, the equimolar concentration of PolyP was shown to disrupt the Lon-DNA complex (Nomura et al., 2004) and Lon colocalization with nucleoid (Zhao et al., 2008). Lon loses DNA-binding ability when cells are exposed to heatshock conditions, which is directly linked to an increase in the amount of damaged proteins (Sonezaki et al., 1995). During starvation, Lon is associated with PolyP granules (Kuroda, 2006). PolyP stimulates Lon to proteolyze ribosomal proteins such 
as L1, L3, and L24 but inhibits proteolysis of SulA protein (an inhibitor of cell division accumulated in response to DNA damage) (Nomura et al., 2004). When Lon is pre-incubated with PolyP, the proteolysis of L24 ribosomal protein is the most efficient (Nomura et al., 2004). Not all PolyP-interacting proteins are degraded by Lon, but all proteins degraded by Lon in a PolyP-dependent manner do form a complex with PolyP (Kuroda, 2006).

Although a complex of protease with PolyP and its general role was uncovered almost two decades ago, we still lack the full mechanistic and physiological insight into this complex formation. To date, no data are available on how/if PolyP affects other proteases in bacterial cells.

\section{THE PROTEOLYSIS OF REPLICATION PROTEINS AND PROTEINS ASSOCIATED WITH DNA REPLICATION}

Not only proteases but also their substrate can interact with DNA or PolyP. Depending on the substrate, the process of proteolysis is specifically controlled and fine-tuned (Table 1). Here, we discuss the proteolysis of selected replication factors and how it affects cell survival.

\section{Replication Initiators}

The replication initiation proteins are the prerequisite factors responsible for initiating DNA replication in various replicons; thus, their degradation allows for rapid arrest of DNA replication. The DnaA, a highly conserved replication initiation protein in bacteria, is an obvious target for cellular proteases. In Caulobacter crescentus, DnaA protein is degraded mainly by Lon, under optimal and stress conditions (Gorbatyuk and Marczynski, 2005; Jonas et al., 2013; Leslie et al., 2015; Liu et al., 2016). It was demonstrated that the DnaA intracellular levels depend on a reduction in DnaA synthesis and fast degradation by the Lon protease. Constitutively, ATP-bound DnaA mutant was shown to be degraded more slowly than wild-type (wt) protein, indicating that degradation of DnaA is linked to DnaA activity or DnaA nucleotide bound state (Liu et al., 2016). Under proteotoxic stress, DnaA is degraded as a result of allosteric activation of Lon by accumulated unfolded substrates and increase in Lon intracellular concentration (Jonas et al., 2013; Figure 1A). Under normal growth conditions, C. crescentus DnaA is proteolyzed at the end of S-phase to ensure that only newly synthesized DnaA is available at the start of each replication round (Jenal, 2009). The overexpression of ClpA in lon-depleted strain restores DnaA degradation, indicating that fail-safe systems are present (Liu et al., 2016).

The regulatory mechanism that controls DNA replication in Escherichia coli by directed proteolysis of replication initiator was termed PolyP-induced DnaA proteolysis (PDAP) (Gross and Konieczny, 2020; Figure 1B). In E. coli cells during amino acid starvation, PolyP induces Lon activity to specifically degrade, DnaA when bound to ADP, but not ATP. When PolyPsynthesizing enzyme (PPK) or Lon protease is depleted in E. coli during stress, DnaA level remains high. Also, the level of DnaA protein variant permanently bound to ATP does not change in stress conditions (Gross and Konieczny, 2020). Both in vivo and in vitro data indicate that when DnaA is converted to ADP-bound form, it is degraded by Lon (Gross and Konieczny, 2020). PolyP interacts with DnaA-ADP, but not DnaA-ATP, which provides an explanation on how Lon targets only DnaAADP for proteolysis. In starvation, as a result of an increase in Lon level and Lon activation by PolyP, the overall DnaA concentration decreases, which leads to the inhibition of DNA replication initiation (Gross and Konieczny, 2020). Since in E. coli (Gross and Konieczny, 2020) and in C. crescentus (Liu et al., 2016) DnaA protein degradation depends on its nucleotide state, it may be crucial for the control of DNA replication. Such possibility is discussed in a recent review on the regulation of Caulobacter DnaA (Felletti et al., 2019). It was also shown that in stress in E. coli, ppGpp affects RNA polymerase activity and thereby superhelicity of replication origin, which leads to DNA replication initiation inhibition (Kraemer et al., 2019). Because ppGpp is not required for PolyP synthesis in E. coli (Crooke et al., 1994), it is very likely that the regulations by ppGpp (Kraemer et al., 2019) and PDAP (Gross and Konieczny, 2020) are independent mechanisms responsible for controlling DNA replication initiation during stress in E. coli.

DnaA participates in the replication initiation of many plasmids, which implies that the replication of plasmid and chromosome in one cell may be coordinately regulated by the inducible degradation of DnaA during stress conditions. This possibility requires to be investigated. It was shown that stability of plasmid DNA is decreased in E. coli proteasedeficient mutants (Bury et al., 2017; Dubiel et al., 2018). Plasmidencoded replication initiators (Rep), e.g., RK2 plasmid TrfA protein, are degraded by Lon and other cytosolic proteases (Wojtkowiak et al., 1993; Wickner et al., 1994; Levchenko et al., 1995; Pierechod et al., 2009; Kubik et al., 2012). The selective proteases activity may affect Rep monomer/dimer ratio and therefore the ability of replication initiator to initiate plasmid DNA replication. DNA stimulates TrfA degradation by Lon (Figure 1C) and ClpAP but inhibits proteolysis by ClpXP and HslUV (Kubik et al., 2012). Similarly, binding of $\lambda \mathrm{O}$ protein, i.e., replication initiator of bacteriophage Lambda, to ori $\lambda$ DNA protects it from degradation by ClpXP (Zylicz et al., 1998). Despite replication initiation control by the Rep concentration and monomer/dimer ratio, the RK2 plasmid replication is also controlled by joining two DNA plasmid particles via TrfA to form handcuff complex, thereby preventing replication reinitiation. E. coli Lon disrupts the handcuff complex by proteolyzing TrfA (Bury et al., 2017).

\section{CtrA}

The response regulator CtrA in C. crescentus is another DNA-binding protein whose level is controlled by proteases. CtrA not only controls transcription of more than a hundred genes (Wojtkowiak et al., 1993) but also inhibits DNA replication initiation (Quon et al., 1996, 1998; Laub et al., 2002). For replication to occur, CtrA must be eliminated at the G1-S transition, and this is carried out by dephosphorylation (Jacobs et al., 2003) and ClpXPmediated proteolysis (Jenal and Fuchs, 1998). Under nutritional stress, CtrA proteolysis is inhibited by ppGpp and PolyP 
TABLE 1 | Comparison of degradation conditions of replication proteins and proteins associated with DNA replication.

\begin{tabular}{|c|c|c|c|c|c|}
\hline Substrate & Function of a substrate & Organism & Protease & $\begin{array}{l}\text { Factors affecting } \\
\text { the proteolysis }\end{array}$ & References \\
\hline \multirow[t]{2}{*}{ DnaA } & $\begin{array}{l}\text { Required for bacterial DNA replication } \\
\text { initiation }\end{array}$ & $\begin{array}{l}\text { Caulobacter } \\
\text { crescentus }\end{array}$ & Lon, ClpAP & $\begin{array}{l}\text { Unfolded } \\
\text { substrates (+) }\end{array}$ & Jonas et al., 2013; Liu et al., 2016 \\
\hline & & Escherichia coli & Lon & PolyP $(+)^{\mathrm{a}}$ & Gross and Konieczny, 2020 \\
\hline \multirow[t]{2}{*}{ TrfA-wt (dimer) } & $\begin{array}{l}\text { Participates in the formation of "handcuff" } \\
\text { of RK2 plasmid particles }\end{array}$ & E. coli & ClpAP, Lon & $\operatorname{DNA}(+)^{\mathrm{b}}$ & Kubik et al., 2012 \\
\hline & & & ClpXP, HslUV & DNA $(-)$ & Kubik et al., 2012 \\
\hline $\begin{array}{l}\text { TrfA G254D/S256L } \\
\text { (monomer) }\end{array}$ & $\begin{array}{l}\text { Participates in replication initiation of RK2 } \\
\text { plasmid }\end{array}$ & E. coli & Lon, ClpAP & DNA (+) & Kubik et al., 2012 \\
\hline RepE & $\begin{array}{l}\text { Participates in replication initiation of } \mathrm{F} \\
\text { plasmid }\end{array}$ & E. coli & Lon & DNA (+) & Karlowicz et al., 2017 \\
\hline$\lambda \mathrm{O}$ & $\begin{array}{l}\text { Participates in replication initiation of phage } \\
\text { lambda }\end{array}$ & E. coli & Lon & DNA (+) & Karlowicz et al., 2017 \\
\hline $\operatorname{Him} A$ & $\begin{array}{l}\text { As a heterodimer with HimD bends DNA in } \\
\text { the structure of oriC, thus facilitating the } \\
\text { replication initiation }\end{array}$ & E. coli & Lon & PolyP (+) & Nomura et al., 2004 \\
\hline Dps & $\begin{array}{l}\text { Protects DNA during starvation and } \\
\text { oxidative stress }\end{array}$ & E. coli & ClpAP, ClpXP & $?^{\mathrm{c}}$ & Stephani et al., 2003 \\
\hline CspD & $\begin{array}{l}\text { Inhibits DNA replication; plays a regulatory } \\
\text { role in chromosomal replication in } \\
\text { nutrient-depleted cells }\end{array}$ & E. coli & Lon & $?$ & Langklotz and Narberhaus, 2011 \\
\hline CtrA & $\begin{array}{l}\text { Controls transcription and inhibits DNA } \\
\text { replication initiation. }\end{array}$ & C. crescentus & ClpXP & $?$ & Jenal and Fuchs, 1998 \\
\hline CcrM & Inhibits DNA replication initiation & C. crescentus & Lon & DNA (+) & Gonzalez et al., 2014 \\
\hline Dnax & Participates in the loading of sliding clamp & C. crescentus & ClpXP & $?$ & Vass and Chien, 2013 \\
\hline SocB & $\begin{array}{l}\text { Binds to sliding clamp and inhibits } \\
\text { elongation of DNA replication }\end{array}$ & C. crescentus & ClpXP & $?$ & Aakre et al., 2013 \\
\hline
\end{tabular}

${ }^{a}(+)$ indicates that the proteolysis is stimulated by DNA, PolyP, or unfolded substrates.

${ }^{b}(-)$ indicates that the proteolysis is inhibited by DNA, PolyP, or unfolded substrates.

$c$ ? indicates that there are no data about impact of DNA, PolyP, or unfolded substrates.

A

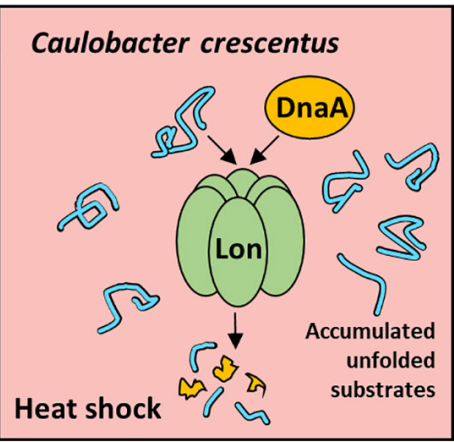

B

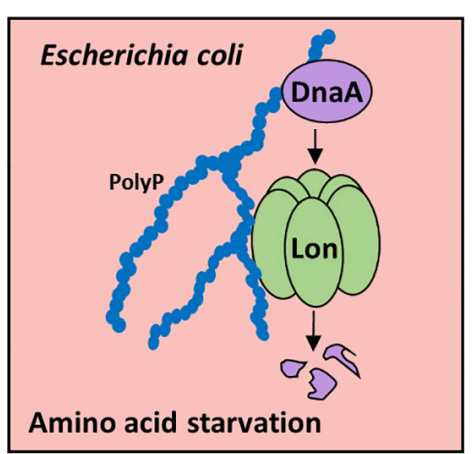

C

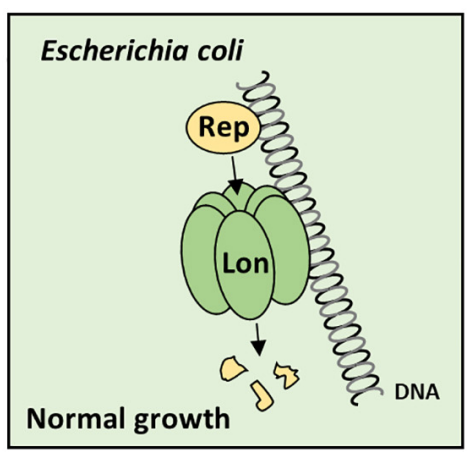

FIGURE 1 | Factors stimulating Lon-dependent proteolysis of replication initiators in Caulobacter crescentus and Escherichia coli during stress or normal growth conditions. (A) In C. crescentus in heat-shock conditions, unfolded substrate accumulation stimulate Lon protease for DnaA degradation, which results in inhibition of DNA replication initiation. (B) In E. coli cells during amino acid starvation, PolyP-induced DnaA proteolysis (PDAP) is launched. PolyP activates Lon protease to degrade DnaA, thereby resulting in the decreasing DnaA level and, consequently, DNA replication initiation arrest. (C) Under normal growth conditions, plasmid replication initiation protein (Rep) degradation by Lon is induced by nucleoprotein complex formation. The protease and substrate interaction with DNA is crucial for efficient degradation. No data are available about Rep proteins stability in stress conditions.

accumulation (Boutte et al., 2012). The proteolysis of CtrA is carried out by ClpXP only when both proteins are localized in the cell pole (Iniesta et al., 2006). This process occurs in the presence of accessory proteins, i.e., CpdR, RcdA, PopA, and cyclic diguanylate (cdG), which accelerate CtrA degradation in vitro. Those accessory proteins are also essential for proteolysis of CtrA bound to DNA (Smith et al., 2014).

\section{CcrM}

In order to complete cell division, the chromosome needs to be fully methylated by the CcrM DNA methyltransferase. This 
methyltransferase CcrM is proteolyzed by Lon to restrict CcrM to most of the cell cycle that prolongs the hemimethylation state of chromosomal DNA during DNA synthesis in C. crescentus (Wright et al., 1996). The ccrM gene transcription is regulated by a positive global regulator CtrA, and the CcrM protein is constitutively degraded by Lon (Wright et al., 1996). Not only DNA was shown to stimulate Lon-mediated proteolysis of CcrM but also CcrM has 10-fold higher affinity for Lon in the presence of DNA, when compared with CcrM to Lon alone (Zhou et al., 2019). The C-terminus of CcrM binds DNA and is recognized by Lon (Zhou et al., 2019). Lon interaction with DNA is not crucial for CcrM proteolysis because CcrM degradation is still observed in cells expressing Lon mutant defective in DNA binding (Zeinert et al., 2018). Therefore, the CcrM level and correct completion of cell cycle depend on the balance between the synthesis and proteolysis of CcrM. CcrM degradation by Lon can also affect the dNTP production in a cell. In $\Delta$ lon strains, an increase in the ribonucleotide reductase (RNR) expression level is observed, which is driven by stabilization of the transcription factor CcrM (Zeinert et al., 2020).

\section{Integration Host Factor}

The integration host factor (IHF) (Nomura et al., 2004) is a histone-like protein responsible for modulation of the DNA condensation (Pettijohn, 1988). IHF is a HimA/HimD heterodimer, which interacts with DNA through specific binding sequence (IBS, IHF binding sequence) and bends DNA in the structure of oriC, thus facilitating the process of replication initiation in E. coli (Ozaki and Katayama, 2012). IHF also participates in regulating the nucleotide state of DnaA. IHF dimers bound to datA sequence promote DnaA-ATP hydrolysis in the DDAH system, thus increasing the pool of DnaA-ADP to prevent overinitiation (Kasho and Katayama, 2013). Moreover, IHF, together with Fis, binds to DARS2 sequence and participates in DnaA-ATP regeneration, which is coupled to cell cycle and growth phase (Kasho et al., 2014). IHF interacts with PolyP (Kornberg, 1995), and its level is regulated by Lon in a PolyPdependent manner (Nomura et al., 2004). The IHF oligomeric state has an impact on this process. HimA degradation is dependent on PolyP and Lon, as opposed to HimD. When both monomers formed heterodimers, neither HimA nor HimD is degraded (Nomura et al., 2004). This suggests that either Lon recognition for HimA is buried at the interface of monomers within heterodimer or a significant structural rearrangement occurs upon dimerization.

\section{CspD}

Upon entry into the stationary phase in E. coli, CspD is expressed and acts as an inhibitor of replication (Yamanaka and Inouye, 1997). Expression of CspD was shown to be activated by (p)ppGpp (Yamanaka and Inouye, 1997). This allows for the adaptation to nutritional changes. CspD was found to be related to persister cell formation (Kim and Wood, 2010). Cellular level of $\mathrm{CspD}$ is regulated in response to growth phase and growth rate by proteolysis. Using electron microscopy (EM), it was shown that $\mathrm{CspD}$ condenses ssDNA; however, those nucleoprotein complexes are distinct from the complex of single-stranded binding protein (SSB) with DNA (Yamanaka et al., 2001). When growth is resumed in nutrient-rich environment, CspD is degraded by Lon (Langklotz and Narberhaus, 2011). The proteolysis of CspD by Lon was reconstituted in vitro and did not require any additives, besides ATP, which indicates that during growth, unknown factors must regulate either Lon activity or CspD availability for degradation.

\section{Dps}

Known as the most abundant protein in a stationary phase in E. coli, Dps was shown to protect DNA during starvation and oxidative stress, by self-aggregation and DNA condensation (Almirón et al., 1992; Azam et al., 1999; Ceci et al., 2004; Frenkiel-Krispin et al., 2004; Melekhov et al., 2015). During DNA damage, Dps also interacts with DnaA in order to delay replication initiation and allow for DNA repair (Chodavarapu et al., 2008). ClpAP and ClpXP degrade Dps during the exponential phase, which leads to a significant reduction in Dps level (Ninnis et al., 2009). Considering the involvement of Dps in various important functions, its level must be tightly controlled.

\section{SocB}

Sliding clamp (a protein responsible for the replisome processivity in DNA replication) is inhibited by SocB, a component of SocB toxin-SocA antitoxin system in C. crescentus (Aakre et al., 2013). The SocB is unstable and constitutively proteolyzed by ClpXP in the presence of SocA. SocB interacts with sliding clamp and inhibits elongation of DNA replication, presumably by outcompeting other proteins from binding sliding clamp. The excessive sliding clamp occupation by SocB leads to premature collapse of replication fork and incomplete cell cycle (Aakre et al., 2013).

\section{DnaX}

For the sliding clamp to be loaded onto DNA, a clamp loader complex is required. In E. coli, this complex contains tau and gamma subunits, which are produced from the same gene, but gamma is shorter due to ribosomal frameshifting (Lee and Walker, 1987). In C. crescentus, which lacks a frameshifting site, ClpXP generates the shorter version, i.e., gamma subunit, which is necessary under normal growth conditions as well as for DNA damage tolerance (Vass and Chien, 2013).

\section{CONCLUSION AND PERSPECTIVES}

In this review, we highlight that directed proteolysis can be stimulated by protease interaction with phosphate-containing molecules such as DNA and PolyP. To date, no structural data are available on such complexes. This specific interaction affects protease activity and selectivity against substrates especially those important in regulation of DNA replication. The current knowledge indicates that among all cytosolic proteases, Lon plays the most important role in the regulation of DNA replication in bacterial cells. We propose that during normal growth, 
it is the nucleoid DNA that provides matrix for Lon and its substrate proteins. During stress, Lon binds to PolyP granules, thereby stimulating degradation of substrates, which also interact with PolyP in stress. The exact molecular mechanism for this activation remains to be elucidated and needs further validation. Application of the cutting-edge structural research, singlemolecule experiments, and trapping approach (Aubin-Tam et al., 2011; Arends et al., 2018; Hu et al., 2018; Fei et al., 2020) should provide insight into the structure-function relationship of Lon, its substrates, adaptor proteins, and complexes with phosphate-containing molecules. Growing evidence indicates that proteolysis is crucial for virulence in many pathogens (Butler et al., 2006; Ingmer and Brøndsted, 2009; Willett et al., 2015). Understanding how directed proteolysis is regulated by phosphate-containing molecules will give insight into microbial stress responses and the regulation of DNA replication.

\section{REFERENCES}

Aakre, C. D., Phung, T. N., Huang, D., and Laub, M. T. (2013). A bacterial toxin inhibits DNA replication elongation through a direct interaction with the $\beta$ sliding clamp. Mol. Cell. 52, 617-628. doi: 10.1016/j.molcel.2013.10.014

Almirón, M., Link, A. J., Furlong, D., and Kolter, R. (1992). A novel DNA-binding protein with regulatory and protective roles in starved Escherichia coli. Genes Dev. 6, 2646-2654. doi: 10.1101/gad.6.12b.2646

Arends, J., Griego, M., Thomanek, N., Lindemann, C., Kutscher, B., Meyer, H. E., et al. (2018). An integrated proteomic approach uncovers novel substrates and functions of the Lon protease in Escherichia coli. Proteomics 18:1800080. doi: 10.1002/pmic. 201800080

Aubin-Tam, M. E., Olivares, A. O., Sauer, R. T., Baker, T. A., and Lang, M. J. (2011). Single-molecule protein unfolding and translocation by an ATP-fueled proteolytic machine. Cell 145, 257-267. doi: 10.1016/j.cell.2011.03.036

Azam, T. A., Iwata, A., Nishimura, A., Ueda, S., and Ishihama, A. (1999). Growth phase-dependent variation in protein composition of the Escherichia coli nucleoid. J. Bacteriol. 181, 6361-6370. doi: 10.1128/jb.181.20.6361-6370.1999

Boutte, C. C., Henry, J. T., and Crosson, S. (2012). ppGpp and polyphosphate modulate cell cycle progression in Caulobacter crescentus. J. Bacteriol. 194, 28-35. doi: 10.1128/jb.05932-11

Burton, R. E., Baker, T. A., and Sauer, R. T. (2005). Nucleotide-dependent substrate recognition by the AAA+ HslUV protease. Nat. Struct. Mol. Biol. 12, 245-251. doi: $10.1038 / \mathrm{nsmb} 898$

Bury, K., Wegrzyn, K., and Konieczny, I. (2017). Handcuffing reversal is facilitated by proteases and replication initiator monomers. Nucleic Acids Res. 45, 39533966. doi: 10.1093/nar/gkx166

Butler, S. M., Festa, R. A., Pearce, M. J., and Darwin, K. H. (2006). Selfcompartmentalized bacterial proteases and pathogenesis. Mol. Microbiol. 60, 553-562. doi: 10.1111/j.1365-2958.2006.05128.x

Ceci, P., Cellai, S., Falvo, E., Rivetti, C., Rossi, G. L., and Chiancone, E. (2004). DNA condensation and self-aggregation of Escherichia coli Dps are coupled phenomena related to the properties of the N-terminus. Nucleic Acids Res. 32, 5935-5944. doi: 10.1093/nar/gkh915

Charette, M. F., Henderson, G. W., Doane, L. L., and Markovitz, A. (1984). DNAstimulated ATPase activity on the lon (CapR) protein. J. Bacteriol. 158, 195-201. doi: 10.1128/jb.158.1.195-201.1984

Charette, M. F., Henderson, G. W., and Markovitz, A. (1981). ATP hydrolysisdependent protease activity of the lon (capR) protein of Escherichia coli K-12. Proc. Natl. Acad. Sci. U.S.A. 78, 4728-4732. doi: 10.1073/pnas.78.8. 4728

Chodavarapu, S., Gomez, R., Vicente, M., and Kaguni, J. M. (2008). Escherichia coli Dps interacts with DnaA protein to impede initiation: a model of adaptive mutation. Mol. Microbiol. 67, 1331-1346. doi: 10.1111/j.1365-2958.2008. 06127.x

\section{AUTHOR CONTRIBUTIONS}

MR, MG, and IK compiled the concept of the mini review. $M R$ and MG wrote the initial version of text. MR and IK prepared the figure and table and wrote the final version of the manuscript. All authors contributed to the article and approved the submitted version.

\section{FUNDING}

This work was supported by the Foundation for Polish Science (TEAM, POIR.04.04.00-00-5C75/17-00). Funding for open access charge: Fundacja na rzecz Nauki Polskiej (TEAM, POIR.04.04.00-00-5C75/17-00).

Crooke, E., Akiyama, M., Rao, N. N., and Kornberg, A. (1994). Genetically altered levels of inorganic polyphosphate in Escherichia coli. J. Biol. Chem. 269, 6290-6295.

Dubiel, A., Wegrzyn, K., Kupinski, A. P., and Konieczny, I. (2018). ClpAP protease is a universal factor that activates the parDE toxin-antitoxin system from a broad host range RK2 plasmid. Sci. Rep. 8, 1-12.

Fei, X., Bell, T. A., Jenni, S., Stinson, B. M., Baker, T. A., Harrison, S. C., et al. (2020). Structures of the ATP-fueled ClpXP proteolytic machine bound to protein substrate. eLife 9:e52774.

Felletti, M., Omnus, D. J., and Jonas, K. (2019). Regulation of the replication initiator DnaA in Caulobacter crescentus. Biochim. Biophys. Acta Gene Regul. Mech. 1862, 697-705. doi: 10.1016/j.bbagrm.2018.01.004

Frees, D., Qazi, S. N., Hill, P. J., and Ingmer, H. (2003). Alternative roles of $\mathrm{ClpX}$ and ClpP in Staphylococcus aureus stress tolerance and virulence. Mol. Microbiol. 48, 1565-1578. doi: 10.1046/j.1365-2958.2003.03524.x

Frenkiel-Krispin, D., Ben-Avraham, I., Englander, J., Shimoni, E., Wolf, S. G., and Minsky, A. (2004). Nucleoid restructuring in stationary-state bacteria. Mol. Microbiol. 51, 395-405. doi: 10.1046/j.1365-2958.2003.03855.x

Fu, G. K., and Markovitz, D. M. (1998). The human LON protease binds to mitochondrial promoters in a single-stranded, site-specific, strand-specific manner. Biochemistry 37, 1905-1909. doi: 10.1021/bi970928c

Goff, S. A., and Goldberg, A. L. (1987). An increased content of protease La, the lon gene product, increases protein degradation and blocks growth in Escherichia coli. J. Biol. Chem. 262, 4508-4515.

Goldberg, A. L., Strnad, N. P., and Swamy, K. S. (1980). Studies of the ATP dependence of protein degradation in cells and cell extracts. Ciba Found. Symp. 75, 227-251. doi: 10.1002/9780470720585.ch15

Gonzalez, D., Kozdon, J. B., McAdams, H. H., Shapiro, L., and Collier, J. (2014). The functions of DNA methylation by CcrM in Caulobacter crescentus: a global approach. Nucleic Acids Res. 42, 3720-3735. doi: 10.1093/nar/gkt1352

Gora, K. G., Cantin, A., Wohlever, M., Joshi, K. K., Perchuk, B. S., Chien, P., et al. (2013). Regulated proteolysis of a transcription factor complex is critical to cell cycle progression in Caulobacter crescentus. Mol. Microbiol. 87, 1277-1289. doi: $10.1111 / \mathrm{mmi} .12166$

Gorbatyuk, B., and Marczynski, G. T. (2005). Regulated degradation of chromosome replication proteins DnaA and CtrA in Caulobacter crescentus. Mol. Microbiol. 55, 1233-1245. doi: 10.1111/j.1365-2958.2004.04459.x

Gottesman, S. (2003). Proteolysis in bacterial regulatory circuits. Annu. Rev. Cell Dev. Biol. 19, 565-587. doi: 10.1146/annurev.cellbio.19.110701.153228

Gray, M. J. (2019). Inorganic polyphosphate accumulation in Escherichia coli is regulated by DksA but not by (p) ppGpp. J. Bacteriol. 201:e0664-18.

Gross, M. H., and Konieczny, I. (2020). Polyphosphate induces the proteolysis of ADP-bound fraction of initiator to inhibit DNA replication initiation upon stress in Escherichia coli. Nucleic Acids Res. 48, 5457-5466. doi: 10.1093/nar/ gkaa217 
Hu, C., Su, C., Yun, Z., Wang, S., He, C., Gao, X., et al. (2018). Real-time identification of the singleness of a trapped bead in optical tweezers. Appl. Opt. 57, 1241-1246. doi: 10.1364/ao.57.001241

Ingmer, H., and Brøndsted, L. (2009). Proteases in bacterial pathogenesis. Res. Microbiol. 160, 704-710. doi: 10.1016/j.resmic.2009.08.017

Iniesta, A. A., McGrath, P. T., Reisenauer, A., McAdams, H. H., and Shapiro, L. (2006). A phospho-signaling pathway controls the localization and activity of a protease complex critical for bacterial cell cycle progression. Proc. Natl. Acad. Sci. U.S.A. 103, 10935-10940. doi: 10.1073/pnas.0604554103

Jacobs, C., Ausmees, N., Cordwell, S. J., Shapiro, L., and Laub, M. T. (2003). Functions of the CckA histidine kinase in Caulobacter cell cycle control. Mol. Microbiol. 47, 1279-1290. doi: 10.1046/j.1365-2958.2003.03379.x

Jenal, U. (2009). The role of proteolysis in the Caulobacter crescentus cell cycle and development. Res. Microbiol. 160, 687-695. doi: 10.1016/j.resmic.2009.09.006

Jenal, U., and Fuchs, T. (1998). An essential protease involved in bacterial cell-cycle control. EMBO J. 17, 5658-5669. doi: 10.1093/emboj/17.19.5658

Jenal, U., and Hengge-Aronis, R. (2003). Regulation by proteolysis in bacterial cells. Curr. Opin. Microbiol. 6, 163-172. doi: 10.1016/s1369-5274(03)00029-8

Jonas, K., Liu, J., Chien, P., and Laub, M. T. (2013). Proteotoxic stress induces a cell-cycle arrest by stimulating Lon to degrade the replication initiator DnaA. Cell 154, 623-636. doi: 10.1016/j.cell.2013.06.034

Kannan, G., Wilks, J. C., Fitzgerald, D. M., Jones, B. D., BonDurant, S. S., and Slonczewski, J. L. (2008). Rapid acid treatment of Escherichia coli: transcriptomic response and recovery. BMC Microbiol. 8:37. doi: 10.1186/14712180-8-37

Karlowicz, A., Wegrzyn, K., Gross, M., Kaczynska, D., Ropelewska, M., Siemiątkowska, M., et al. (2017). Defining the crucial domain and amino acid residues in bacterial Lon protease for DNA binding and processing of DNAinteracting substrates. J. Biol. Chem. 292, 7507-7518. doi: 10.1074/jbc.m116. 766709

Kasho, K., Fujimitsu, K., Matoba, T., Oshima, T., and Katayama, T. (2014). Timely binding of IHF and Fis to DARS2 regulates ATP-DnaA production and replication initiation. Nucleic Acids Res. 42, 13134-13149. doi: 10.1093/nar/ gku1051

Kasho, K., and Katayama, T. (2013). DnaA binding locus datA promotes DnaAATP hydrolysis to enable cell cycle-coordinated replication initiation. Proc. Natl. Acad. Sci. U.S.A. 110, 936-941. doi: 10.1073/pnas.1212070110

Khattar, M. M. (1997). Overexpression of the hslVU operon suppresses SOSmediated inhibition of cell division in Escherichia coli. FEBS Lett. 414, 402-404. doi: 10.1016/s0014-5793(97)01024-7

Kim, Y., and Wood, T. K. (2010). Toxins Hha and CspD and small RNA regulator Hfq are involved in persister cell formation through MqsR in Escherichia coli. Biochem. Biophys. Res. Commun. 391, 209-213. doi: 10.1016/j.bbrc.2009.11.033

Kornberg, A. (1995). Inorganic polyphosphate: toward making a forgotten polymer unforgettable. J. Bacteriol. 177, 491-496. doi: 10.1128/jb.177.3.491-496.1995

Kraemer, J. A., Sanderlin, A. G., and Laub, M. T. (2019). The stringent response inhibits DNA replication initiation in E. coli by modulating supercoiling of oriC. mBio 10:e01330-19.

Kubik, S., Wegrzyn, K., Pierechod, M., and Konieczny, I. (2012). Opposing effects of DNA on proteolysis of a replication initiator. Nucleic Acids Res. 40, 11481159. doi: 10.1093/nar/gkr813

Kuroda, A. (2006). A polyphosphate-lon protease complex in the adaptation of Escherichia coli to amino acid starvation. Biosci. Biotechnol. Biochem. 70, 325-331. doi: 10.1271/bbb.70.325

Kuroda, A., Murphy, H., Cashel, M., and Kornberg, A. (1997). Guanosine tetraand pentaphosphate promote accumulation of inorganic polyphosphate in Escherichia coli. J. Biol. Chem. 272, 21240-21243. doi: 10.1074/jbc.272.34.21240

Kuroda, A., Nomura, K., Ohtomo, R., Kato, J., Ikeda, T., Takiguchi, N., et al. (2001). Role of inorganic polyphosphate in promoting ribosomal protein degradation by the Lon protease in E. coli. Science 293, 705-708. doi: 10.1126/science. 1061315

Kurokawa, K., Nishida, S., Emoto, A., Sekimizu, K., and Katayama, T. (1999). Replication cycle-coordinated change of the adenine nucleotide-bound forms of DnaA protein in Escherichia coli. EMBO J. 18, 6642-6652. doi: 10.1093/emboj/ 18.23.6642

Langklotz, S., and Narberhaus, F. (2011). The Escherichia coli replication inhibitor $\mathrm{CspD}$ is subject to growth-regulated degradation by the Lon protease. Mol. Microbiol. 80, 1313-1325. doi: 10.1111/j.1365-2958.2011.07646.x
Laub, M. T., Chen, S. L., Shapiro, L., and McAdams, H. H. (2002). Genes directly controlled by CtrA, a master regulator of the Caulobacter cell cycle. Proc. Natl. Acad. Sci. U.S.A. 99, 4632-4637. doi: 10.1073/pnas.062065699

Lee, A. L., Chen, Y. D., Chang, Y. Y., Lin, Y. C., Chang, C. F., Huang, S. J., et al. (2014). Structural basis for DNA-mediated allosteric regulation facilitated by the AAA+ module of Lon protease. Acta Crystallogr. Sect. D Biol. Crystallogr. 70, 218-230. doi: 10.1107/s139900471302631x

Lee, A. Y. L., Hsu, C. H., and Wu, S. H. (2004). Functional domains of Brevibacillus thermoruber Lon protease for oligomerization and DNA binding role of $\mathrm{N}$-terminal and sensor and substrate discrimination domains. J. Biol. Chem. 279, 34903-34912. doi: 10.1074/jbc.m403562200

Lee, S. H., and Walker, J. R. (1987). Escherichia coli DnaX product, the tau subunit of DNA polymerase III, is a multifunctional protein with single-stranded DNAdependent ATPase activity. Proc. Natl. Acad. Sci. U.S.A. 84, 2713-2717. doi: 10.1073/pnas.84.9.2713

Leslie, D. J., Heinen, C., Schramm, F. D., Thüring, M., Aakre, C. D., Murray, S. M., et al. (2015). Nutritional control of DNA replication initiation through the proteolysis and regulated translation of DnaA. PLoS Genet. 11:e10053432. doi: 10.1371/journal.pgen.1005342

Levchenko, I., Luo, L., and Baker, T. A. (1995). Disassembly of the Mu transposase tetramer by the ClpX chaperone. Genes Dev. 9, 2399-2408. doi: 10.1101/gad.9. 19.2399

Lin, Y. C., Lee, H. C., Wang, I., Hsu, C. H., Liao, J. H., Lee, A. Y. L., et al. (2009). DNA-binding specificity of the Lon protease $\alpha$-domain from Brevibacillus thermoruber WR-249. Biochem. Biophys. Res. Commun. 388, 62-66. doi: 10. 1016/j.bbrc.2009.07.118

Liu, J., Francis, L. I., Jonas, K., Laub, M. T., and Chien, P. (2016). ClpAP is an auxiliary protease for DnaA degradation in Caulobacter crescentus. Mol. Microbiol. 102, 1075-1085. doi: 10.1111/mmi.13537

Liu, T., Lu, B., Lee, I., Ondrovièová, G., Kutejová, E., and Suzuki, C. K. (2004). DNA and RNA binding by the mitochondrial lon protease is regulated by nucleotide and protein substrate. J. Biol. Chem. 279, 13902-13910. doi: 10.1074/ jbc.m309642200

Lu, B., Liu, T., Crosby, J. A., Thomas-Wohlever, J., Lee, I., and Suzuki, C. K. (2003). The ATP-dependent Lon protease of Mus musculus is a DNA-binding protein that is functionally conserved between yeast and mammals. Gene 306, 45-55. doi: 10.1016/s0378-1119(03)00403-7

Magnusson, L. U., Farewell, A., and Nystrom, T. (2005). ppGpp: a global regulator in Escherichia coli. Trends Microbiol. 13, 236-242. doi: 10.1016/j.tim.2005. 03.008

Martin, A., Baker, T. A., and Sauer, R. T. (2008). Diverse pore loops of the AAA + ClpX machine mediate unassisted and adaptor-dependent recognition of ssrA-tagged substrates. Mol. Cell. 29, 441-450. doi: 10.1016/j.molcel.2008. 02.002

Melekhov, V. V., Shvyreva, U. S., Timchenko, A. A., Tutukina, M. N., Preobrazhenskaya, E. V., Burkova, D. V., et al. (2015). Modes of Escherichia coli Dps interaction with DNA as revealed by atomic force microscopy. PLoS One 10:e0126504. doi: 10.1371/journal.pbio.000126504

Minami, N., Yasuda, T., Ishii, Y., Fujimori, K., and Amano, F. (2011). Regulatory role of cardiolipin in the activity of an ATP-dependent protease, Lon, from Escherichia coli. J. Biochem. 149, 519-527. doi: 10.1093/jb/mvr036

Nicoloff, H., Perreten, V., and Levy, S. B. (2007). Increased genome instability in Escherichia coli lon mutants: relation to emergence of multiple-antibioticresistant (Mar) mutants caused by insertion sequence elements and large tandem genomic amplifications. Antimicrob. Agents Chemother. 51, 1293-1303. doi: 10.1128/aac.01128-06

Ninnis, R. L., Spall, S. K., Talbo, G. H., Truscott, K. N., and Dougan, D. A. (2009). Modification of PATase by L/F-transferase generates a ClpS-dependent N-end rule substrate in Escherichia coli. EMBO J. 28, 1732-1744. doi: 10.1038/emboj. 2009.134

Nomura, K., Kato, J., Takiguchi, N., Ohtake, H., and Kuroda, A. (2004). Effects of inorganic polyphosphate on the proteolytic and DNA-binding activities of Lon in Escherichia coli. J. Biol. Chem. 279, 34406-34410. doi: 10.1074/jbc. $\mathrm{m} 404725200$

Osbourne, D. O., Soo, V. W., Konieczny, I., and Wood, T. K. (2014). Polyphosphate, cyclic AMP, guanosine tetraphosphate, and c-di-GMP reduce in vitro Lon activity. Bioengineered 5, 264-268. doi: 10.4161/bioe. 29261 
Ozaki, S., and Katayama, T. (2012). Highly organized DnaA-oriC complexes recruit the single-stranded DNA for replication initiation. Nucleic Acids Res. 40, 1648-1665. doi: 10.1093/nar/gkr832

Pettijohn, D. E. (1988). Histone-like proteins and bacterial chromosome structure. J. Biol. Chem. 263, 12793-12796.

Pierechod, M., Nowak, A., Saari, A., Purta, E., Bujnicki, J. M., and Konieczny, I. (2009). Conformation of a plasmid replication initiator protein affects its proteolysis by ClpXP system. Protein Sci. 18, 637-649.

Puri, N. (2016). HspQ Functions as a Novel Specificity-Enhancing Factor for the AAA+Lon Protease. Doctoral thesis, The Graduate School, Stony Brook University, Stony Brook, NY.

Quon, K. C., Marczynski, G. T., and Shapiro, L. (1996). Cell cycle control by an essential bacterial two-component signal transduction protein. Cell 84, 83-93. doi: 10.1016/s0092-8674(00)80995-2

Quon, K. C., Yang, B., Domian, I. J., Shapiro, L., and Marczynski, G. T. (1998). Negative control of bacterial DNA replication by a cell cycle regulatory protein that binds at the chromosome origin. Proc. Natl. Acad. Sci. U.S.A. 95, 120-125. doi: 10.1073/pnas.95.1.120

Racki, L. R., Tocheva, E. I., Dieterle, M. G., Sullivan, M. C., Jensen, G. J., and Newman, D. K. (2017). Polyphosphate granule biogenesis is temporally and functionally tied to cell cycle exit during starvation in Pseudomonas aeruginosa. Proc. Natl. Acad. Sci. U.S.A. 114, E2440-E2449.

Rao, N. N., Gomez-Garcia, M. R., and Kornberg, A. (2009). Inorganic polyphosphate: essential for growth and survival. Annu. Rev. Biochem. 78, 605-647. doi: 10.1146/annurev.biochem.77.083007.093039

Rao, N. N., and Kornberg, A. (1996). Inorganic polyphosphate supports resistance and survival of stationary-phase Escherichia coli. J. Bacteriol. 178, 1394-1400. doi: 10.1128/jb.178.5.1394-1400.1996

Schweder, T., Lee, K. H., Lomovskaya, O., and Matin, A. (1996). Regulation of Escherichia coli starvation sigma factor (sigma s) by ClpXP protease. J. Bacteriol. 178, 470-476. doi: 10.1128/jb.178.2.470-476.1996

Simmons, L. A., Grossman, A. D., and Walker, G. C. (2008). Clp and Lon proteases occupy distinct subcellular positions in Bacillus subtilis. J. Bacteriol. 190, 6758-6768. doi: 10.1128/jb.00590-08

Smith, S. C., Joshi, K. K., Zik, J. J., Trinh, K., Kamajaya, A., Chien, P., et al. (2014). Cell cycle-dependent adaptor complex for ClpXP-mediated proteolysis directly integrates phosphorylation and second messenger signals. Proc. Natl. Acad. Sci. U.S.A. 111, 14229-14234. doi: 10.1073/pnas.1407862111

Sonezaki, S., Okita, K., Oba, T., Ishii, Y., Kondo, A., and Kato, Y. (1995). Protein substrates and heat shock reduce the DNA-binding ability of Escherichia coli Lon protease. Appl. Microbiol. Biotechnol. 44, 484-488. doi: 10.1007/ s002530050586

Stephani, K., Weichart, D., and Hengge, R. (2003). Dynamic control of Dps protein levels by ClpXP and ClpAP proteases in Escherichia coli. Mol. Microbiol. 49, 1605-1614. doi: 10.1046/j.1365-2958.2003.03644.x

Sugiyama, N., Minami, N., Ishii, Y., and Amano, F. (2013). Inhibition of Lon protease by bacterial lipopolysaccharide (LPS) though inhibition of ATPase. Adv. Biosci. Biotechnol. 4, 590-598. doi: 10.4236/abb.2013. 44077

Traxler, M. F., Summers, S. M., Nguyen, H. T., Zacharia, V. M., Hightower, G. A., Smith, J. T., et al. (2008). The global, ppGpp-mediated stringent response to amino acid starvation in Escherichia coli. Mol. Microbiol. 68, 1128-1148. doi: 10.1111/j.1365-2958.2008.06229.x

Vass, R. H., and Chien, P. (2013). Critical clamp loader processing by an essential AAA+ protease in Caulobacter crescentus. Proc. Natl. Acad. Sci. U.S.A. 110, 18138-18143. doi: 10.1073/pnas.13113 02110

Wah, D. A., Levchenko, I., Baker, T. A., and Sauer, R. T. (2002). Characterization of a specificity factor for an AAA+ ATPase: assembly of SspB dimers with ssrA-tagged proteins and the ClpX hexamer. Chem. Biol. 9, 1237-1245. doi: 10.1016/s1074-5521(02)00268-5
Waxman, L., and Goldberg, A. L. (1985). Protease La, the lon gene product, cleaves specific fluorogenic peptides in an ATP-dependent reaction. J. Biol. Chem. 260, 12022-12028.

Wickner, S., Gottesman, S., Skowyra, D., Hoskins, J., McKenney, K., and Maurizi, M. R. (1994). A molecular chaperone, ClpA, functions like DnaK and DnaJ. Proc. Natl. Acad. Sci. U.S.A. 91, 12218-12222. doi: 10.1073/pnas.91.25.12218

Willett, J. W., Herrou, J., Briegel, A., Rotskoff, G., and Crosson, S. (2015). Structural asymmetry in a conserved signaling system that regulates division, replication, and virulence of an intracellular pathogen. Proc. Natl. Acad. Sci. U.S.A. 112, E3709-E3718.

Wojtkowiak, D., Georgopoulos, C., and Zylicz, M. (1993). Isolation and characterization of ClpX, a new ATP-dependent specificity component of the Clp protease of Escherichia coli. J. Biol. Chem. 268, 22609-22617.

Wright, R., Stephens, C., Zweiger, G., Shapiro, L., and Alley, M. R. (1996). Caulobacter Lon protease has a critical role in cell-cycle control of DNA methylation. Genes Dev. 10, 1532-1542. doi: 10.1101/gad.10.12.1532

Xie, F., Li, G., Zhang, Y., Zhou, L., Liu, S., Liu, S., et al. (2016). The Lon protease homologue LonA, not LonC, contributes to the stress tolerance and biofilm formation of Actinobacillus pleuropneumoniae. Microb. Pathog. 93, 38-43. doi: 10.1016/j.micpath.2016.01.009

Yamanaka, K., and Inouye, M. (1997). Growth-phase-dependent expression of $\operatorname{cspD}$, encoding a member of the CspA family in Escherichia coli. J. Bacteriol. 179, 5126-5130. doi: 10.1128/jb.179.16.5126-5130.1997

Yamanaka, K., Zheng, W., Crooke, E., Wang, Y. H., and Inouye, M. (2001). CspD, a novel DNA replication inhibitor induced during the stationary phase in Escherichia coli. Mol. Microbiol. 39, 1572-1584. doi: 10.1046/j.1365-2958.2001. 02345.x

Zakrzewska-Czerwińska, J., Jakimowicz, D., Zawilak-Pawlik, A., and Messer, W. (2007). Regulation of the initiation of chromosomal replication in bacteria. FEMS Microbiol. Rev. 31, 378-387. doi: 10.1111/j.1574-6976.2007.00070.x

Zehnbauer, B. A., Foley, E. C., Henderson, G. W., and Markovitz, A. (1981). Identification and purification of the Lon+ $($ capR+) gene product, a DNAbinding protein. Proc. Natl. Acad. Sci. U.S.A. 78, 2043-2047. doi: 10.1073/pnas. 78.4.2043

Zeinert, R. D., Baniasadi, H., Tu, B. P., and Chien, P. (2020). The Lon protease links nucleotide metabolism with proteotoxic stress. Mol. Cell 79, 758-767.e6.

Zeinert, R. D., Liu, J., Yang, Q., Du, Y., Haynes, C., and Chien, P. (2018). A legacy role for DNA binding of Lon protects against genotoxic stress. bioRxiv [Preprint], doi: 10.1101/317677

Zhao, J., Niu, W., Yao, J., Mohr, S., Marcotte, E. M., and Lambowitz, A. M. (2008). Group II intron protein localization and insertion sites are affected by polyphosphate. PLoS Biol. 6:e150. doi: 10.1371/journal.pbio.0060150

Zhou, X., Wang, J., Herrmann, J., Moerner, W. E., and Shapiro, L. (2019). Asymmetric division yields progeny cells with distinct modes of regulating cell cycle-dependent chromosome methylation. Proc. Natl. Acad. Sci. U.S.A. 116, 15661-15670. doi: 10.1073/pnas.1906119116

Zylicz, M., Liberek, K., Wawrzynow, A., and Georgopoulos, C. (1998). Formation of the preprimosome protects $\lambda \mathrm{O}$ from RNA transcription-dependent proteolysis by ClpP/ClpX. Proc. Natl. Acad. Sci. U.S.A. 95, 15259-15263. doi: 10.1073/pnas.95.26.15259

Conflict of Interest: The authors declare that the research was conducted in the absence of any commercial or financial relationships that could be construed as a potential conflict of interest.

Copyright (c) 2020 Ropelewska, Gross and Konieczny. This is an open-access article distributed under the terms of the Creative Commons Attribution License (CC BY). The use, distribution or reproduction in other forums is permitted, provided the original author(s) and the copyright owner(s) are credited and that the original publication in this journal is cited, in accordance with accepted academic practice. No use, distribution or reproduction is permitted which does not comply with these terms. 